\title{
Prevalence of Human Rift Valley Fever Virus as a Bio-threat in Asian Countries after COVID-19 Lockdown
}

\author{
Anika Bushra ${ }^{1}$, Khandaker Sabit Bin Razzak², Mohammad Nabil Hossain ${ }^{3}$, Divya Jain ${ }^{4}$, \\ ASM Sarwar ${ }^{5}$, Soaibur Rahman ${ }^{6}$
}

\begin{abstract}
${ }^{1}$ Research Student, Department of Biochemistry and Microbiology, North South University, Dhaka, Bangladesh; ${ }^{2}$ Research Student, Department of Public Health, American International University-Bangladesh, Dhaka, Bangladesh; ${ }^{3}$ Research Student, College of Biological and Pharmaceutical Sciences, China Three Gorges University, Hubei, China; ${ }^{4} \mathrm{Ph} . \mathrm{D}$. Scholar, Department of Bioscience and Biotechnology, Banasthali Vidyapith, Rajasthan, India; ${ }^{5}$ Chief Researcher, Department of Research and Development, Topbright, Dhaka, Bangladesh; ${ }^{6}$ B.Sc. Student, Department of Genetic Engineering and Biotechnology, East West University, Dhaka, Bangladesh
\end{abstract}

\section{To the editor,}

The Rift Valley fever is a regional disease as it is mostly occurs in some specific regions like Arabian Peninsula, sub-Saharan Africa region, Egypt, and Madagascar ${ }^{1-3}$. This fever becomes an alarming issue for not only human and animal health, but also for the production, as it turns as a significant zoonotic arboviral disease ${ }^{2}$. Africa is the main central point where large epizootics happen at aperiodic intervals. Floodwater-breeding mosquitoes are the main reasons behind Rift Valley Fever and also for the association of epizootics, where mosquito vectors find an appropriate weather condition for breeding which is increased due to heavy rainfall ${ }^{1-2}$. So in this case, it can be said that both rainfall and Rift Valley fever has a close connection with each other ${ }^{3}$.

Enzootic circulation is identified as the main reason behind the existence of a natural host which performs its duty as a cryptic carrier especially in inter-epizootic periods normal or low rainfall seasons. This fever has not been only transmitted in Africa, but also has been reached other parts of the world because of an increasing number of infected animals' migration to the new areas ${ }^{4}$. Now-a-days, this disease has drawn attention in the public health sector because of its imperceptible transmission and the geographical characteristics ${ }^{5}$.

In spite of that, zoonosis has become one of the major alarming problems in today's world. A lot of new report updates on human infections are found.
Among all, one report stated that both potential of public health and socio-economic effects of future breakout to this fever 5 . If any person gets in contact with the affected animals or their body fluids, he/she can be directly infected; and this is one of the reason behind the transmission of this disease ${ }^{4-7}$. Furthermore, this transmission can make the present condition more hazardous ${ }^{4-7}$.

Since few years, the vertical transmission of this fever has been observed and recorded. In the same way of transmission the Rift valley fever are shared by both human beings and animals as significant vector borne disease with mosquitoes ${ }^{10-11}$. As a result, infected person can embrace fetal death even. ${ }^{11}$.

In the case of human beings, the transmission of this disease occurs in two ways; either from the direct contact with infected animals or products related to them, or even from mosquito bites ${ }^{4-6}$. Because of the importation of mosquito vector through direct flight, this disease epidemiology has reached in an extended way to the new areas like East Asia 12. Now-a-days, Korea has drawn attention regarding the rift valley fever as for the last few years, sero-prevalence in local animals has been observed there. In spite of having a risk factor regarding vector, a "disease-free" safe situation is declared in Korea ${ }^{12}$.

Although Japan is not facing any pandemic situation regarding Rift valley fever. Currently, China is going through an undeniable condition 
regarding this disease. China is the country which detected the first human imported case of this fever from Angola, where the male patient was suffering from acute febrile illness. This single incident creates the importance of taking necessary steps regarding rift valley control in China ${ }^{12}$. Horn of Africa (Kenya, Uganda, Rwanda) is going through the acute manifestation of RVF, even Mayotte (a French Island part of Comoros archipelago) is not free from danger ${ }^{13-14}$. Besides, the dengue outbreak has been a serious issue in the Indian Ocean area (La Reunion, Mayotte, and Seychelles islands) where the early implementation of the warning system regarding the interaction among people, mosquitos, arboviruses, and other natural factors should be needed badly.

Food and Agriculture Organization of the United Nation states an assumption that RVF outbreaks can cause disruption in the livestock sector through depleting the future generation of victimized herds; as a result, both socio-economic and food-related trouble can happen regarding daily vulnerable households. The RVF poses a challenge both too, disturbing animal exploitation in communities by having a significant impact on local animal markets and by impacting household funds from animals and thus hampering health and education systems. Besides, according to the Intergovernmental Authority on Development (IGAD), RVF is becoming an alarming issue for both economic improvement and safety of the nation; it also strictly proposes for a regional level implementation regarding this fever control. The latest FAO RVF forecast in May 2020 confirms that both animals and humans remain in danger of RVF incidence in the area in the next few months, either as a consequence of environmental conditions and/or by the movement of animals, and calls for a desperately required preparation for any future RVF epidemic, especially by cooperation with One Health coordination ${ }^{13}$. In Kabale District, there have been 5 major cases ${ }^{13}$. On 17 December 2019, 28 new cases of RVF were also registered in The Federal Ministry of Health $(\mathrm{FMoH})$ of $\operatorname{Sudan}^{14}$. Then a case of fatal human Rift Valley Fever (RVF) was identified for the second time in Uganda in December $2019^{15}$.

Both direct and indirect exposure to the blood and organs of infected animals can be the main reason behind a lot of human infections. There are several explanations why this RVF is transmitted: animal tissue handling through processing, butchering, animal life care, medical treatment or removal of carcasses or fetuses, etc. Mainly the risk factor can be grown at an alarming rate especially for the working-class people like herders, farmers, slaughterhouse workers, and veterinarians; they can be infected highly by this fever. So in this present hazardous pandemic condition like COVID-19, we should treat this Rift Valley fever (RVF) seriously; if we do not pay heed to this serious disease and avoid it, is near future, affected cases will be increased as it is also increasing currently.

Acknowledgement: We are thankful to the cordial guidance to North South University, American International UniversityBangladesh, China Three Gorges University, Hubei, China, Department of Bioscience and Biotechnology, Banasthali Vidyapith, Rajasthan, India and Department of Genetic Engineering and Biotechnology, East West University, Dhaka.

\section{Reference}

1. Gerdes GH. Rift Valley fever. Revue Scientifique et Technique 2004; 23(2):613.

2. The Epidemiology of Rift Valley Fever in Mayotte: Insights and Perspectives from 11 Years of Data. Raphaëlle Métras, Lisa Cavalerie, Laure Dommergues, Philippe Mérot, W. John Edmunds, Matt J. Keeling, Catherine Cêtre-Sossah, Eric Cardinale 2016; 10(6):e0004783.

3. Pretorius A, Oelofsen MJ, Smith MS, van der Ryst E. Rift Valley Fever Virus: a Seroepidemiologic Study of Small Terrestrial Vertebrates in South Africa. The American Journal of Tropical Medicine and Hygiene 1997; 57(6):693-698.

4. Ganter M. Zoonotic risks from small ruminants. The American Journal of Tropical Medicine and Hygiene 2015; 181(1-2): 2 .

5. Mark O. Nanyingi, Peninah Munyua, Stephen G. Kiama, Gerald M. Muchemi, Samuel M. Thumbi, Austine O. Bitek, Bernard Bett, Reese M. Muriithi, M. Kariuki Njenga. A systematic review of Rift Valley Fever epidemiology 19312014. Infection Ecology \& Epidemiology 2015; 5(1): 3.

6. Marycelin Baba, Daniel K Masiga, Rosemary Sang, and Jandouwe Villinger. Has Rift Valley fever virus evolved with increasing severity in human populations in East Africa? Emerging Microbes \& Infection 2016; 5(6):e58.

7. Karen L Mansfield, Ashley C Banyard, Lorraine McElhinney, Nicholas Johnson, Daniel L Horton, Luis M Hernández-Triana, Anthony R Fooks . Rift Valley fever virus: A review of diagnosis and vaccination, and implications for emergence in Europe. Vaccine 2015; 33(42): 5520-5531.

8. Ishag Adam, Mubarak S. Karsany. Case report: Rift Valley Fever with vertical transmission in a pregnant Sudanese woman. Journal of Medical Virology 2008; 80: 929.

9. Haider M. Arishi, Ali Y. Aqeel, Mohamed Al Hazmi. Vertical transmission of fatal Rift Valley fever in a newborn. Annals of Tropical Paediatrics 2006; 26(3): 251-253.

10. Viroj Wiwanitkit. Emerging Rift Valley fever in China: What should be known?. Asian Pacific Journal of Tropical Biomedicine 2016; 6(9):727-729.

11. Hyun Joo Kim, Hye-Young Jeoung, Jung-Yong Yeh, YunSang Cho, Jeong-Soo Choi, Ji-Youn Lee, In-Soo Cho, HanSang Yoo. Serological surveillance studies confirm the Rift Valley fever virus free status in South Korea.. Tropical Animal Health and Production 2015; 47(7): 1427-1430.

12. World Health Organization. Rift Valley fever. https://www.who.int/news-room/fact-sheets/detail/rift-valleyfever (accessed 5 September 2020)

13. Food and Agriculture Organization of the United Nation. FAO and IGAD are joining forces against Rift Valley Fever. https://rr-africa.oie.int/wp-content/uploads/2020/05/fao-igadrvf-statement.pdf (accessed 5 September 2020) 
14. Reliefweb. Outbreak update - Rift Valley fever in Sudan, 14 December 2019. https://reliefweb.int/report/sudan/outbreakupdate-rift-valley-fever-sudan-14-december-2019 (accessed 5 September 2020)

15. Outbreak News Today. Uganda reports 2nd fatal Rift Valley fever case. http://outbreaknewstoday.com/ugandareports-2nd-fatal-rift-valley-fever-case-51670/ (accessed 5 September 2020).

[Bangladesh Journal of Infectious Diseases, October 2020;7(suppl_2):S72-S74]

Correspondence: Khandaker Sabit Bin Razzak, Research Student, Department of Public Health, American International University Bangladesh, Dhaka, Bangladesh; Cell no.:
+8801834990613; Email: sabit.kh06@ gmail.com; ORCID ID: https://orcid.org/0000-0001-9610-8945

Conflict of interest: Authors declare that there is no conflict of interest.

How to cite this article: Bushra A, Razzak KSB, Hossain MN, Jain D, Sarwar ASM, Rahman S. Prevalence of Human Rift Valley Fever Virus as a Bio-threat in Asian Countries after COVID-19 Lockdown. Bangladesh J Infect Dis 2020;7(suppl_2):S72-S74

Copyright: (O2020. Bushra et al. Published by Bangladesh Journal of Infectious Diseases. This article is published under the Creative Commons CC BY-NC License (https://creativecommons.org/licenses/by-nc/4.0/). This license permits use, distribution and reproduction in any medium, provided the original work is properly cited, and is not used for commercial purposes. 